\title{
Has suicide become an occupational hazard of practising medicine?
}

\author{
— Cite as: CMAJ 2018 June 18;190:E752-3. doi: 10.1503/cmaj.109-5614
}

Posted on cmajnews.com on May 29, 2018.

$\mathrm{T}$ hree young female doctors have jumped to their deaths from the 33-storey apartment building across from Mount Sinai St. Luke's Hospital in New York City in the past two years. Their colleagues told reporters that the hospital has done little to investigate or help them cope with the deaths. Following the most recent suicide, resident physicians said the hospital warned them against talking to the media before they were told there had been a death. Grief counsellors were available, but residents said they didn't have time or feel safe to speak with them. Several noted they were regularly working over the legal limit of 80 hours per week. There was no collective opportunity to grieve.

It's a story that's too common in medicine. Doctors have the highest suicide rate of any profession, according to a literature review recently presented at the American Psychiatric Association conference. As many as 40 physicians per 100000 die by suicide each year, more than double the rate of the general population. In the United Sates, it's estimated that one doctor dies by suicide every day.

Female physicians are particularly vulnerable, says Dr. Omotola T'Sarumi, lead author of the study. Although they attempt suicide less often than other women, their completion rate is as much as four times higher than the general population and equal to that of male physicians. Doctors who are transitioning in some way - finishing medical school, seeking residency positions, entering retirement - also face higher risks of suicide.

"This is not a topic that is much discussed," except following the news of a death, says T'Sarumi. Based on her find- ings, she says, suicide should be treated as an occupational hazard of medicine. "We are becoming the patients and not seeking help when we need it the most because of fear, stigma and penalty."

It's a view that's gaining traction in Canada, too. "Our work environments are unhealthy and it's supported by a culture of giving and made worse in modern times by a culture of efficiencies and bureaucracies," says Dr. Michael Kaufmann, medical director emeritus of the Ontario Medical Association's physician health program.

People don't enter medical training at a higher than average risk for suicide or mental illness, he explains. But from medical school onward, the common experi- ence is too much demand and not enough relief. "You're constantly being asked to deliver more and you're running on a chronic state of depletion," Kaufmann says. Eventually, something gives. "At the end of the line, suicide is one of the most dramatic and tragic outcomes."

Efforts to prevent these deaths have often been aimed at increasing individuals' coping skills, notes Kaufmann. "But that becomes frustrating and, after a point, insulting to the individual who is in this unhealthy environment where anyone would suffer." Those who become more resilient often end up being given more work, he adds. "The system continues to take advantage of the giving mentality of

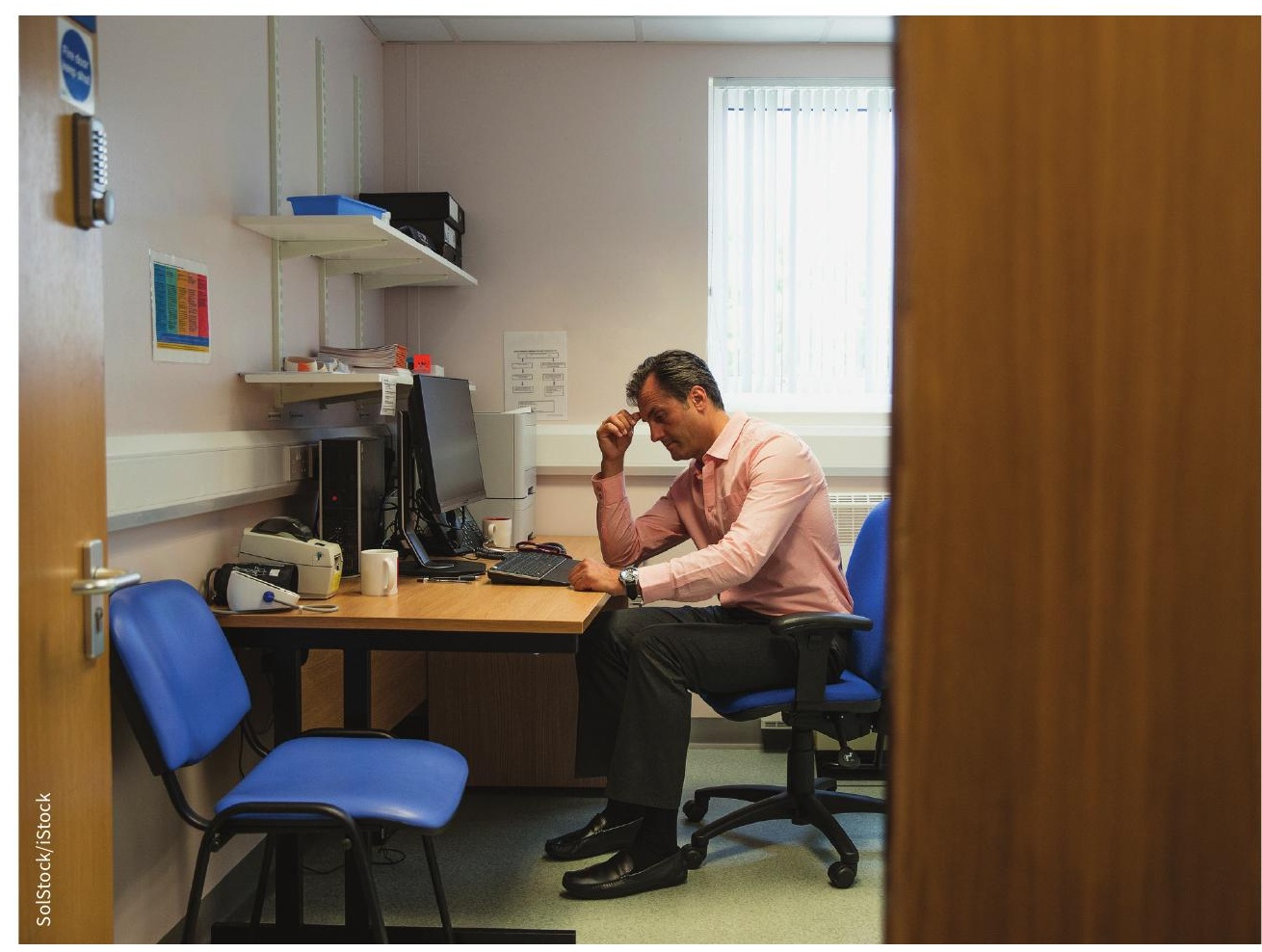

Physician health experts say the health system shares responsibility for the profession's high rates of suicide. 
highly competent, highly qualified people who are willing to put patients first, to an extreme that's unhealthy."

Health care needs to be redesigned to promote the wellness of both workers and patients, Kaufmann says. "We know that there are more medical errors when doctors are burned out, and we also know that healthy providers actually do have an immediate and direct impact on the overall health of their patients."

Continuing to ignore the role of the health system in physician suicide is "naive at best," says Dr. Derek Puddester, former director of physician health at the Canadian Medical Association. There's no formal tracking of these deaths in Canada but, anecdotally, the rate is probably the same or higher than in the United States, he says. Beyond improving supports for individuals, there needs to be national coordination to study the problem and embed wellness benchmarks into accreditation standards for hospitals, universities and other institutions, Puddester says.

The fraught relationship between physicians, government and regulators is one point of stress in medicine. Another problem is a toxic culture that Puddester attributes to a lack of compassion. "There can be a very cool, mean, dismissive streak when a doctor is vulnerable, impaired or viewed as different."

Young people should be made aware of these realities when they're considering the profession, Puddester adds. When he talks with teenagers and first-year medical students, "it's a balancing act of saying 'this is what we currently know' versus 'wow, this is soul-crushing data and change your mind." 'At very least, potential medical students deserve to be well informed about the risks and benefits of a career in medicine. "That, to me, seems ethical and reasonable."

Lauren Vogel, CMAJ 